\title{
Use of NK1 C3 monoclonal antibody in the assessment of benign and malignant melanocytic lesions
}

\author{
RONA M MACKIE, IRENE CAMPBELL, MARLYN L TURBITT \\ From the Department of Dermatology, University of Glasgow, Glasgow G11 6NU
}

SUMMARY The monoclonal antibody NK1 C3, synthesised by the Netherlands Cancer Institute, has been used to assess its value in the diagnosis of melanocytic lesions. The antigen recognised by this antibody is not denatured by formalin fixation, with the result that the antibody can be used for retrospective studies on conventionally processed material.

Positive results were obtained in primary melanoma $(18 / 18)$, secondary melanoma $(21 / 21)$, junctional and compound naevi (32/32), intradermal naevi (9/12), congenital naevi (3/3), so called dysplastic naevi (13/13), blue naevi (5/5), and Spitz tumours (3/14). Non-melanocytic tumours were tested for comparison. The results showed relative but not complete specificity of the antibody for melanocytic tumours, with positive results only in breast and prostate tumours (2/6 and 2/5 respectively). Negative results were obtained with basal and squamous cell carcinoma, appendage tumours, neural tumours, and apudomas.

The staining pattern of NK1 C3 was compared with that of antibodies to S100 protein and to neurone specific enolase. Compared with $\mathrm{S} 100$ protein NK1 C3 gave stronger staining of a higher percentage of cells in the 12 specimens in which a direct comparison was made. Antibody raised against neurone specific enolase in sheep gave very poor results with heavy background staining. We suggest that NK1 C3 is a useful addition to the battery of monoclonal antibodies of value to the diagnostic histopathologist.

In the past three years a large number of monoclonal antibodies have been raised against melanoma cells. Most have been raised against short term cell lines, or membrane fractions, and as a result tend to react with surface membrane antigens. These are often disrupted or destroyed by conventional histological fixation and preparation techniques, and as a result the antibodies react only with fresh frozen tissue. This is obviously a major disadvantage as far as routine surgical pathology is concerned, in that no retrospective studies on an unexpectedly pleomorphic tissue can be performed. Although the practice of surgeons and pathologists is evolving to utilise the "new morphology," with reservation of a small portion of frozen tissue for such work, those who work with primary malignant melanoma are understandably reluctant to divide up a specimen in such a way that the Breslow thickness measurement may be inaccurate. This problem does

Accepted for publication 15 December 1983 not arise when one is dealing with a large tumour sample, but it does arise with small primary lesions in which the diagnosis is not clinically apparent.

In this paper we report our experience with the use of the NK1 C3 monoclonal antibody as an aid to the diagnosis of melanocytic lesions. It does not discriminate between benign and malignant melanocytic lesions, but it does show a useful level of specificity for melanocytic versus non-melanocytic lesions.

\section{Material and methods}

The monoclonal antibody NK1 C3 was made available to us by Dr C Vennegoor and Dr P Rümke, to whom we express our gratitude. Details of the synthesis and characterisation have already been published.' Briefly, plasma membrane fractions of the human melanoma line Me Wo were used to immunise BALB-C mice, and spleen cells were then fused with the murine myeloma line P3 X $63 \mathrm{Ag} 8$. 
Table 1 Results of staining of melanocytic lesions with NK1 C3

\begin{tabular}{|c|c|c|c|}
\hline & No examined & \multicolumn{2}{|c|}{$\begin{array}{l}\text { No giving positive } \\
\text { results }\end{array}$} \\
\hline \multicolumn{2}{|l|}{$\begin{array}{l}\text { *Primary cutaneous malignant } 18 \\
\text { melanoma }\end{array}$} & \multicolumn{2}{|l|}{ 18) } \\
\hline *Secondary melanoma deposits & s 21 & 21 & \\
\hline $\begin{array}{l}\text { Junctional and compound } \\
\text { naevi (acquired) }\end{array}$ & 22 & $22)$ & \\
\hline Intradermal naevi (acquired) & 12 & 9 & \\
\hline Congenital naevi & 3 & 3 & $55 / 69(80 \%)$ \\
\hline "Dysplastic" naevi & 13 & 13 & \\
\hline Blue naevi & 5 & 5 & \\
\hline Spitz tumours (spindle \& & 14 & 3 & \\
\hline $\begin{array}{l}\text { Juvenile melanoma") } \\
\text { Total }\end{array}$ & 118 & 104 & $(88 \%)$ \\
\hline
\end{tabular}

All tissues were cut from formalin fixed and paraffin processed blocks.

Normal melanocytes at periphery of lesions were not stained. Similarly, no higher level epidermal dendritic cells (presumed Langerhans' cells) were stained.

*Staining was not uniform in adjacent histologically similar cells but varied from intense to weak to almost negative within these lesions.

Cloned cells were found to secrete antibody which reacted with cytoplasmic contents of melanoma cells. The antibody is an $\mathrm{IgG}_{1}$, and the antigenicity of the cytoplasm components recognised is preserved in formalin fixed and paraffin processed tissue sections.

\section{MATERIAL TESTED}

This is listed in Tables 1 and 2. The bulk of the material was tested retrospectively using material drawn from our files. In 13 specimens of melanocytic lesions prospective testing was carried out and the reactivity of the antibody compared on frozen and fixed tissue.

\section{OTHER ANTIBODIES USED FOR COMPARATIVE STUDIES}

Antibody to $S 100$ protein was kindly made available to us by $\mathrm{Dr} G$ Rowden. This antibody reacts with melanocytic cells and other cells derived from neural crest. $^{2-5}$ It also identifies epidermal Langerhans' cells ${ }^{6}$ and the cells comprising granular cell myoblastoma. ${ }^{7}$ Antibody raised in sheep against neurone specific enolase was kindly made available by $\mathrm{Dr}$ Thompson, of Cambridge. A similar antibody is now commercially available. This antibody has also been advocated as a diagnostic aid in melanoma and neuroblastoma. ${ }^{8} 9$

\section{IMMUNOHISTOLOGICAL METHOD}

For NK1 C3 antibody, paraffin sections were taken to water and treated with $0.2 \% \mathrm{HCl}$ in methanol with $0.1 \% \mathrm{H}_{2} \mathrm{O}_{2}$ to block endogenous peroxidase. After rinsing in water they were washed in Tris saline for $5 \mathrm{~min}$ and incubated for $15 \mathrm{~min}$ in $1 / 5$ normal rabbit serum. Excess was removed and NK1 $\mathrm{C} 3$ overlaid in a dilution of $1 / 50$ for $60 \mathrm{~min}$ at $37^{\circ} \mathrm{C}$. The samples were then washed in Tris saline for 15 min and incubated in $1 / 20$ rabbit antimouse IgG peroxidase conjugate (Dako) with $50 \%$ normal human serum for $45 \mathrm{~min}$ at $20^{\circ} \mathrm{C}$. After washing for 10 min slides were immersed in $0.03 \%$ DAB (Sigma) for 8-10 min, washed in tap water, counterstained with haematoxylin, dehydrated, and mounted.

For S100 protein, paraffin sections were taken to water and treated with $0.2 \% \mathrm{HCl}$ in methanol with $0.1 \% \mathrm{H}_{2} \mathrm{O}_{2}$ to block endogenous peroxidase. After rinsing in water they were washed in Tris saline for 5 min and incubated for $15 \mathrm{~min}$ in $1 / 5$ rabbit normal serum. Excess was removed and 1/50 diluted rabbit anti-S100 protein overlaid for $60 \mathrm{~min}$ at $37^{\circ} \mathrm{C}$. Sections were washed in Tris saline, then incubated with $1 / 100$ swine antirabbit IgG (Dako) with $50 \%$ normal human serum for $15 \mathrm{~min}$ at $20^{\circ} \mathrm{C}$. After washing in Tris, incubation proceeded with $1 / 100$ rabbit antiperoxidase-peroxidase complex (Dako) for $15 \mathrm{~min}$ at $20^{\circ} \mathrm{C}$. Thereafter the procedure was as for NK1 C3.

\section{Results}

These are listed in Table 1 for melanocytic lesions and Table 2 for non-melanocytic lesions.

\section{MALIGNANT MELANOMA}

All 18 samples of primary and 21 samples of secondary malignant melanoma gave positive results with both membrane and cytoplasmic staining. The intensity of the staining throughout the lesion was

Table 2 Results of staining of non-melanocytic lesions with NK1 C3

No examined $\begin{aligned} & \text { No giving positive } \\ & \text { results }\end{aligned}$

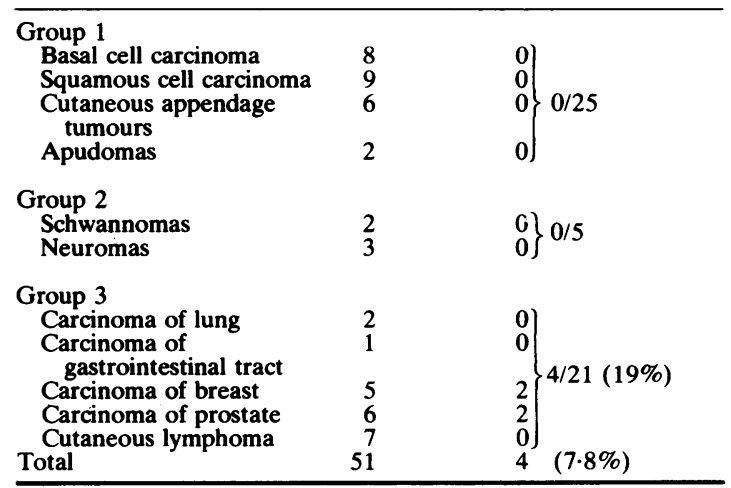


not uniform, however, with adjacent cells showing on occasion very strong staining and very faint staining (Fig. 1). Normal melanocytes at the periphery of the lesion were not stained, allowing accurate delineation of the lateral margin of spread of the tumour.

In the primary melanomata the antibody identified cells admixed with lymphocytes in the infiltrate which often occupies these lesions. This permitted more accurate measurements of Breslow thickness, and comparison of the measurement using haematoxylin and eosin stained sections with that using antibody stained sections indicated that both overestimates and underestimates were made of Breslow thickness in haematoxylin and eosin stained sections. In lesions with dense underlying infiltrates the Breslow thickness measurement tended to be falsely thick as the deepest inflammatory cell was often measured: in contrast, in lesions with a mild and desultory scattered infiltrate the tendency was to produce a falsely thin measurement and ignore isolated infiltrating tumour cells. The problem is illustrated in Fig. 2.
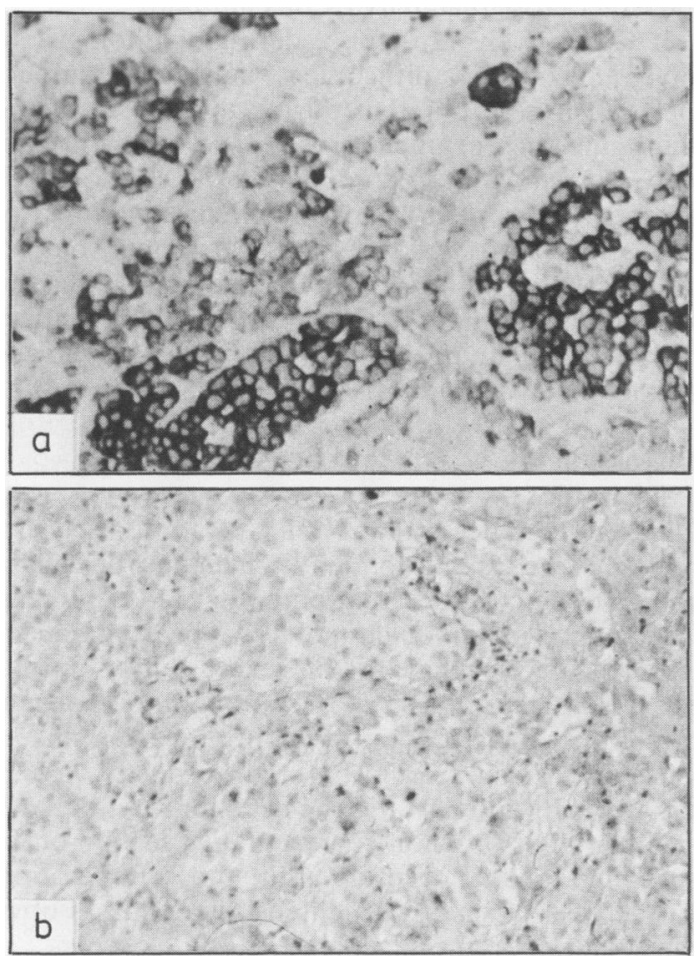

Fig. 1 NK1 C3 staining of primary malignant melanoma. Sequential sections showing (a) peroxidase reaction product and (b) haematoxylin and eosin section. Note that not all cells are stained and that the intensity is variable.
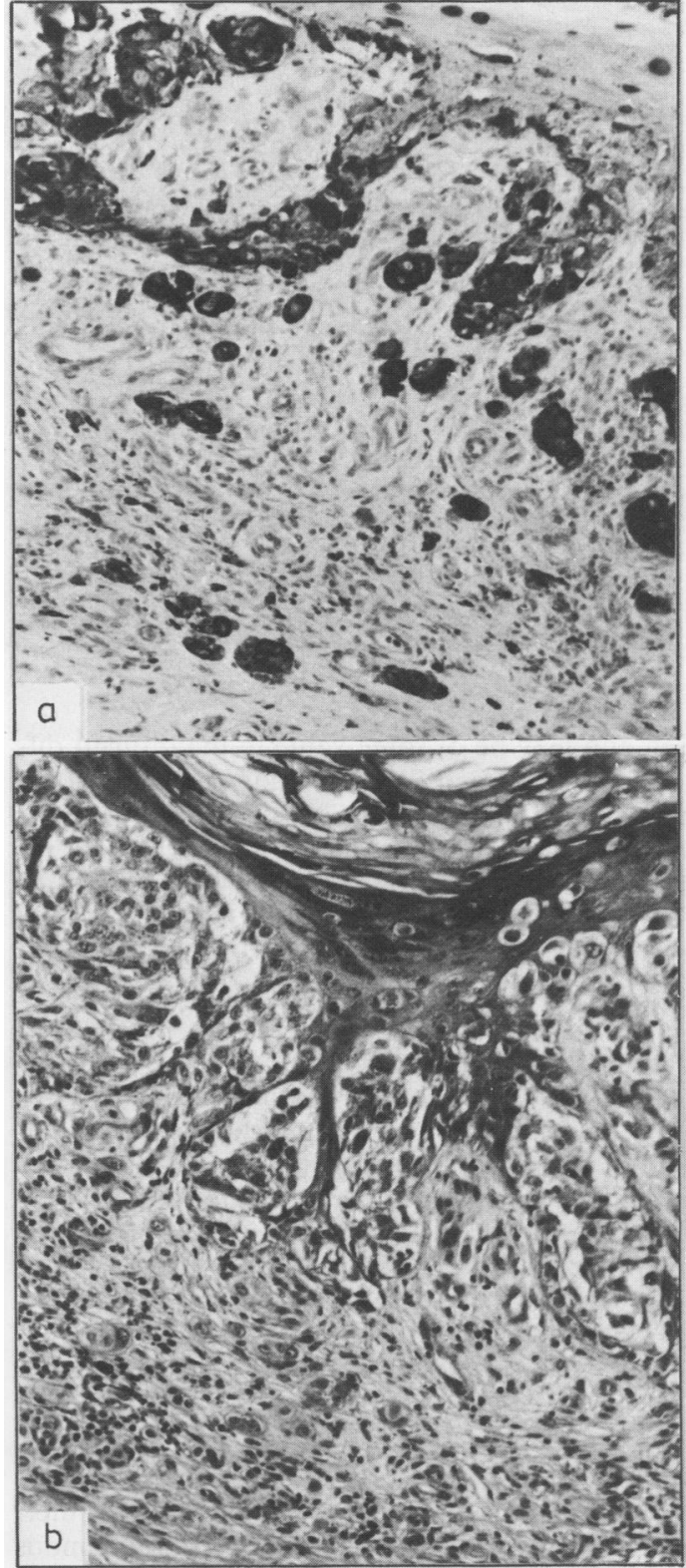

Fig. 2 NK1 C3 staining of melanoma cells with an underlying lymphocytic infiltrate. The antibody greatly facilitates the identification of single cell dermal invasion. Compare with haematoxylin and eosin section (b).

\section{BENIGN MELANOCYTIC LESIONS}

Of 69 benign melanocytic tumours studied, 55 were positive. Eleven of the negative sections were from Spitz naevi, and three from intradermal naevi. This is of interest with regard to the ontogeny of the Spitz 


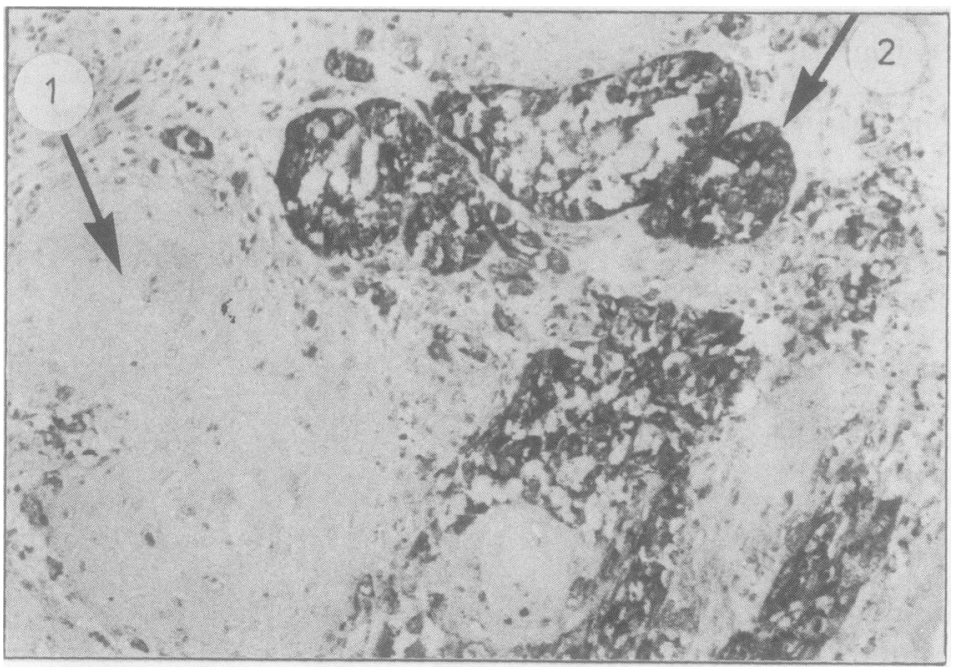

Fig. $3 \quad N K 1$ C3 staining of lesion present for six months on the cheek. Because of the apparently invasive tongues of epithelial cells (arrow 1) this was originally interpreted as squamous cell carcinoma. Note, however, the strongly positive melanocytic cells above the keratinocytes (arrow 2). Four months later the patient returned with secondary melanoma.

lesion and may be of some value in the difficult differentiation between Spitzoid malignant melanoma and true Spitz naevus. If positive, the lesion may be either tumour, but a negative result would be supportive evidence in favour of a benign lesion.

Strength of staining was variable in all the benign melanocytic lesions, both within a lesion and between different cells and lesions of the same histological type. In general, intradermal naevi were lightly stained, while junctional and dysplastic naevi showed strong staining. This was not, however, constant enough to be utilised in diagnosis.

In 13 cases (six melanoma and seven naevi) it was possible to compare the staining pattern of NK1 C3 in frozen and paraffin processed samples from the same piece of tissue. In all cases the staining pattern was clearer and stronger on paraffin processed tissue. This is an unusual observation in the case of a monoclonal antibody, but clearly is an advantage for retrospective studies.

\section{NON-MELANOCYTIC TUMOURS (Table 2)}

The non-melanocytic tumours were chosen for their importance to the dermatopathologist (squamous carcinoma, basal cell carcinoma, and appendage tumours-group 1); for the ontogenetical relation to melanocytes (neural tumours-group 2); and for their importance in the diagnosis of anaplastic tumour masses presenting as secondary tumours of unknown derivation (gastrointestinal, breast, or prostatic tumours and lymphomata-group 3). The antibody showed no reactivity with either group 1 or group 2 tumours, but did show reactivity with some of the group 3 tumours. These were breast, with $2 / 6$ positive results, and prostate, with $2 / 5$ positive results. Other tumours tested in this section were negative, but obviously a wider range of nonmelanocytic tumours would be required to establish the exact cross reactivity of this antibody.

It is relatively rare for a dermatopathologist to have diagnostic difficulties between tumours included in group 1, but during the course of the study one such example arose. A 68 year old man was referred with a red nodule on the cheek, which had been present for six months. Excision biopsy of the lesion suggested squamous carcinoma, but six months later the patient returned with enlarged submandibular nodes, which contained secondary melanoma. Staining of the primary tumour showed strong positivity with NK1 C3 (Fig. 3).

\section{Discussion}

Our results indicate that NK1 C3 can be used in a retrospective fashion to identify melanocytic cells in conventionally processed pathological specimens. The antigen identified has not as yet been characterised but the fact that it is preserved during normal processing permits use of this antibody on conventional formalin fixed and paraffin processed material. This, of course, allows for retrospective use of the antibody and obviates the need for retention of a small and possibly non-representative section of the specimen for snap freezing at the time of operation. In the case of small pigmented lesions this is obviously an important advantage.

The antibody appears to react preferentially, but not exclusively, with lesions of melanocytic derivation. The $100 \%$ positivity rate of malignant melanoma and $88 \%$ positivity rate for all melanocy- 
Table 3 Comparative staining of NK1 C3 and S100 protein antibodies in 12 malignant melanomas

\begin{tabular}{llll}
\hline & $\begin{array}{l}\text { Intensity of staining graded } \\
+ \text { to }+++\end{array}$ & $\begin{array}{l}\text { \% of apparent tumour cells } \\
\text { stained }\end{array}$ & General comments \\
\hline NK1 C3 & $8+++3++1+$ & $\begin{array}{l}\text { Range 10-70\% } \\
\text { Mean 50\% } \\
\text { Range 5-40\% } \\
\text { Mean 10\% }\end{array}$ & $\begin{array}{l}\text { Staining variability between adjacent cells } \\
\text { Positive staining of peripheral nerve and Langerhans' cells } \\
\text { at times made interpretation difficult }\end{array}$ \\
\hline
\end{tabular}
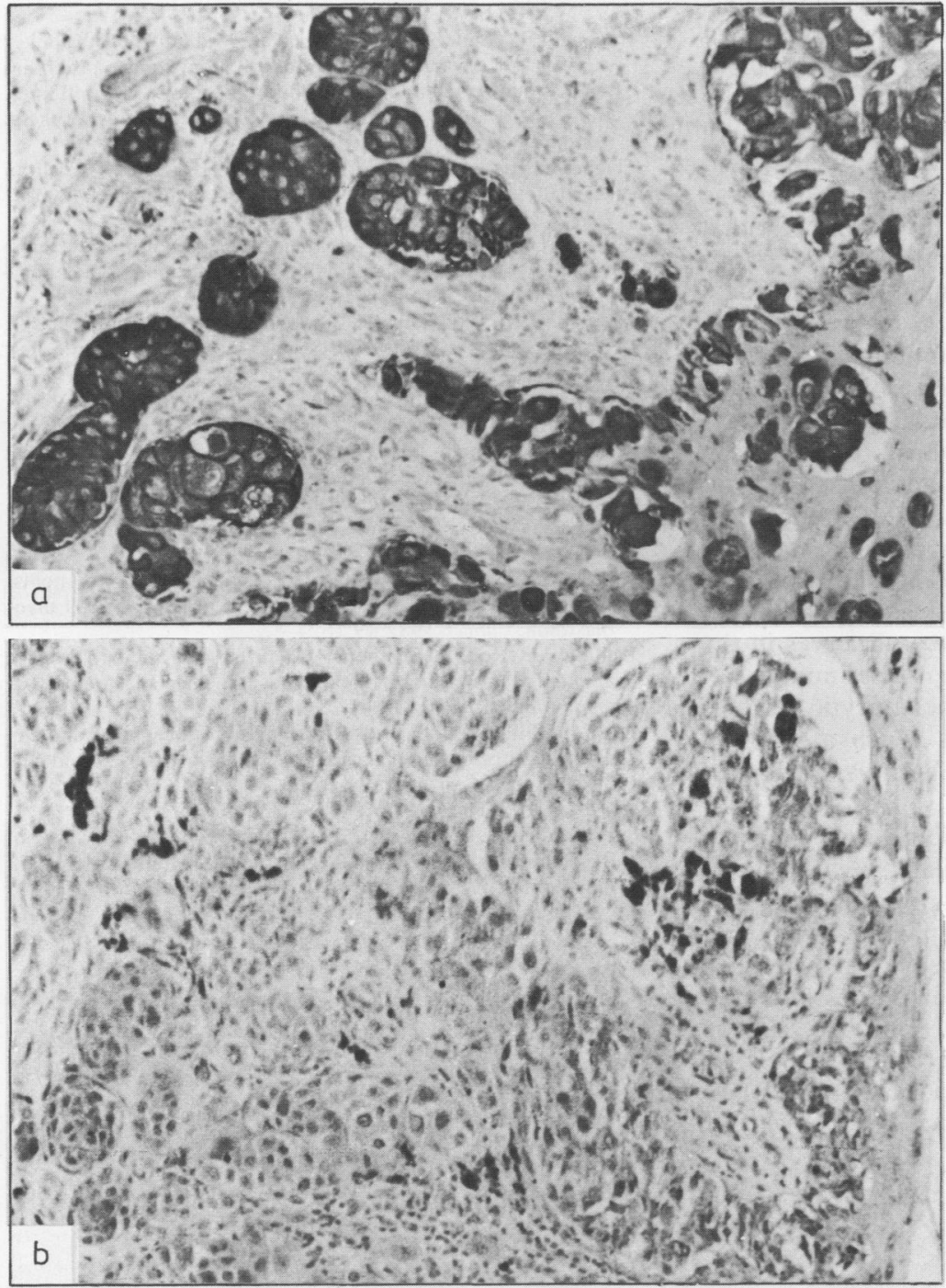

Fig. 4 (a) NK1 C3 staining of primary malignant melanoma. (b) S100 staining for comparison. Note strikingly less intensity of staining and also a lower percentage of cells showing any staining at all, particularly at the dermoepidermal interface. 
tic lesions compared with $\mathbf{7 \cdot 5 \%}$ for non-melanocytic lesions indicates clearly that positive staining is useful evidence in favour of melanocytic derivation of a tumour mass of uncertain origin, but it cannot be an absolute guide. The variation in staining intensity of adjacent morphologically similar cells is consistent with current thoughts on tumour cell heterogeneity and intralesional transformation. None of the malignant melanocytic lesions studied by us has given negative results, and thus absence of staining could be regarded as useful evidence against the melanocytic derivation of a lesion. An example of a situation in which this confirmation could be useful supporting evidence is in the identification of a secondary tumour mass of uncertain origin in the skin. The differential diagnosis may include melanoma, lymphoma, and metastases from non-cutaneous primaries such as breast or gastrointestinal tract.

Malignant and benign melanocytic tumours are both stained by this antibody, so that it cannot be of value in the commoner situation where the differential diagnosis lies between an active proliferating naevus and an early melanoma. It is of interest that most of the negative melanocytic lesions in our series were Spitz naevi. We cannot as yet explain this observation, but identification of the antigenic determinant against which the antibody is directed may throw some light on the essential difference between Spitz naevi and compound naevi.

The other antibodies with which NK1 C3 can reasonably be compared include antibodies to $\mathrm{S} 100$ protein and neurone specific enolase (Table 3 ). In our 12 cases $S 100$ protein antibody yielded fainter staining of fewer cells (Fig. 4) compared with NK1 $\mathrm{C} 3$ and had the disadvantage of staining epidermal Langerhans' cells and also peripheral nerves in the dermis. Like NK1 C3, it does not discriminate between benign and malignant melanocytic lesions, and, moreover, it stains lesions which are not of melanocytic derivation, such as granular cell myoblastoma.

Commercially available antibody to neurone specific enolase is currently available only in ovine form. We have found that this antibody gives very strong non-specific staining on epidermal cells and dermal fibroblasts. Efforts at absorption to reduce this staining have not as yet been successful. This problem, together with reports of Springall $\mathrm{et} \mathrm{al}^{10}$ of neurone specific enolase staining in only six of 58 melanomas, all of which were positive with $\mathrm{S} 100$ protein, suggests that at present neurone enolase is of limited value in the identification of malignant melanocytic lesions.

We therefore suggest that NK1 C3 is a useful monoclonal antibody in the identification of melanoma cells in formalin fixed and paraffin processed material. It works reliably on tissue sections and should be considered when assembling a library of monoclonal antibodies either for identification of anaplastic tumours or for further study of the biochemistry of the melanocyte in normal and pathological states.

\section{References}

' Hageman P, Vennegoor C, van der Valk M, Landegent J, Jonker A, van der Mispel L. Reactions of monoclonal antibodies against human melanoma with different tissues and cell lines. In: Peeters H, ed. Protides of the biological fuids, Vol 89, Oxford: Pergamon Press, 1982.

${ }^{2}$ Gaynor R, Irie R, Morton D, Herschmann HR, Jones P, Cochran A. S100 protein. A marker for human malignant melanomas? Lancet 1981;i:869-71.

${ }^{3}$ Cochran AJ, Wen D-R, Herschmann HR, Gaynor RB. Detection of $S 100$ protein as an aid to the identification of melanocytic tumours. Int $J$ Cancer 1982;30.

${ }^{4}$ Stefansson K, Wollmann R, Jerkovic M. S100 protein in soft tissue tumours derived from Schwann cells and melanocytes. Am J Pathol 1982;106:261-8.

${ }^{5}$ Nakajima T, Watanabe S, Sayo Y, Kameya T, Shimosatu Y, Ishihara K. Immunohistochemical demonstration of $\mathrm{S} 100$ protein in malignant melanoma and pigmented naevus and its diagnostic application. Cancer 1982;50:912-8.

${ }^{6}$ Rowden G, Connolly EM, Winkelmann RK. Cutaneous histiocytosis X. The presence of $\mathbf{S} 100$ protein and its use in diagnosis. Arch Dermatol 1983;119:553-9.

${ }^{7}$ Nakazatu Y, Ishizeki J, Takahashi K, Yamaguchi H. Immunohistochemical localization of S100 protein in granular cell myoblastoma. Cancer 1982;49:1624-8.

${ }^{8}$ Dhillon AP, Rode J, Leathem A. Neurone specific enolase. An aid to the diagnosis of melanoma and neuroblastome. Histopathology 1982;6:81-92.

' Rode J, Dhillon AP, Papedoki L. Immunohistochemical staining of granular cell tumour for neurone specific enolase. Evidence in support of a neural origin. Diagnostic Histopathology 1982;5:205-11.

${ }^{10}$ Springall DR, Gu J, Cocchia D, Michetti F, et al. The value of $\mathrm{S}-100$ immunostaining as a diagnostic tool in human malignant melanomas. Virchows Arch (Pathol Anat) 1983;400:331-43.

Requests for reprints to: Professor Rona M MacKie, Department of Dermatology, University of Glasgow, Glasgow G12, Scotland. 